\title{
Review of mental health promotion interventions in schools
}

\author{
Michelle O'Reilly ${ }^{1} \cdot$ Nadzeya Svirydzenka $^{2} \cdot$ Sarah Adams ${ }^{3} \cdot$ Nisha Dogra $^{1}$
}

Received: 14 February 2018 / Accepted: 30 April 2018 / Published online: 11 May 2018

(c) The Author(s) 2018

\begin{abstract}
Purpose The prevalence of mental disorders amongst children and adolescents is an increasing global problem. Schools have been positioned at the forefront of promoting positive mental health and well-being through implementing evidence-based interventions. The aim of this paper is to review current evidence-based research of mental health promotion interventions in schools and examine the reported effectiveness to identify those interventions that can support current policy and ensure that limited resources are appropriately used.

Methods The authors reviewed the current state of knowledge on school mental health promotion interventions globally. Two major databases, SCOPUS and ERIC were utilised to capture the social science, health, arts and humanities, and education literature.

Results Initial searches identified 25 articles reporting on mental health promotion interventions in schools. When mapped against the inclusion and exclusion criteria, 10 studies were included and explored. Three of these were qualitative and seven were quantitative.

Conclusions A range of interventions have been tested for mental health promotion in schools in the last decade with variable degrees of success. Our review demonstrates that there is still a need for a stronger and broader evidence base in the field of mental health promotion, which should focus on both universal work and targeted approaches to fully address mental health in our young populations.
\end{abstract}

Keywords Mental health promotion $\cdot$ Children $\cdot$ Schools $\cdot$ Interventions

\section{Introduction}

Globally $10-20 \%$ of children and young people experience a mental disorder [28]; and this is increasing [26]. Additionally, it is estimated that $50 \%$ of adults with disorders

Michelle O'Reilly

mjo14@le.ac.uk

Nadzeya Svirydzenka

nadzeya.svirydzenka@dmu.ac.uk

Sarah Adams

sjca1@le.ac.uk

Nisha Dogra

nd13@le.ac.uk

1 The Greenwood Institute, University of Leicester, Westcotes Drive, Leicester LE3 0QU, UK

2 Faculty of Health and Life Sciences, De Montfort University, The Gateway, Leicester LE1 9BG, UK

3 School of Education, University of Leicester, University Road, Leicester LE1 7RH, UK experienced them prior to age 15 [25]. To address this, it is important to pay attention to promotion and prevention practice, with schools being well-placed to deliver. This is because of the amount of time young people spend in this environment [49]. The focus of this review is therefore, on universal mental health promotion interventions in schools rather than those that target high-risk individuals or where health education is part of the treatment of a mental health disorder.

\section{Mental health promotion and prevention: operational definitions}

The World Health Organisation [58] defines mental health promotion as actions to create living conditions and environments that support mental health and allow people to adopt and maintain healthy lifestyles. These include actions to optimise people's chances of experiencing better mental health. The WHO noted that fundamental to mental health promotion are actions that facilitate an environment that 
respects and protects basic civil, political, socio-economic and cultural rights. Without the security and freedom provided by these rights, arguably it is difficult to maintain high levels of mental health. The WHO argued that mental health policies should include mental health promotion and not be limited to the health sector, but also involve education, labour, justice, transport, environment, housing, and welfare.

The WHO defines mental illness prevention as encompassing the reduction of incidence, prevalence, and recurrence of illness. Prevention strategies tend to be useful in targeting groups 'at-risk' to prevent them from developing disorders. However, although differentiated, it is important to note that the distinction is less rigid for young populations, because children develop skills as they mature [3] and skill development aimed at promoting well-being can have preventative effects [46].

\section{Mental health promotion in schools}

Schools are pervasive environments in young peoples' lives and can positively impact on their mental health, mitigating some negative impacts of other social factors. However, for some, schools can present as considerable sources of stress, worry, and unhappiness [12], which can hinder academic attainment. In focusing on promotion, therefore, it is important to consider the educational context as a natural environment in which it is possible to build rights of agency, security, and personal freedom in young people, whilst recognising any limitations this may have.

Schools are positioned at the forefront of promoting positive mental health. This is an important way of tackling the growing prevalence of mental disorders worldwide. This has prompted the publication of numerous guidelines and policies in how this could be achieved in the UK and internationally. Recently, in England the government pledged that all secondary (high) schools will receive mental health training by 2020 and each school should have a mental health champion [38]. Similarly, governments in Wales and Scotland have produced policies and statements to advocate the promotion of positive mental health in school-aged children [43, 57]. Furthermore, such thinking is reflected internationally as several countries have been exploring ways of integrating health and education [2].

Evidently, mental health promotion in schools needs to be achieved through the provision of a continuum of intervention programmes. Weist and Murray [55] argued that these should focus on social and emotional learning, competence for all students, and actively involve young people, schools and communities. The authors further argued that quality is central, and many factors need to be accounted for:

- Inclusive approach.
- Build programmes responsive to student, school and community needs, building connections between resources.

- Focus on reducing barriers to student learning through programmes, based on evidence.

- Emphasise and provide support for systematic quality assessment and improvement.

- Ensure staff are engaged and supported.

- Ensure efforts are sensitive to developmental and diversity factors of students.

- Build interdisciplinary relationships in schools, strong teams and coordinating mechanisms.

Weist and Murray [55] observed that for change to happen, training and involvement from a range of people is needed to create a cultural shift in the educational context. This is mirrored in other western countries, where involvement of several people is considered necessary for successful mental health promotion programmes in schools (e.g. [32, 42]). Furthermore, developing partnerships between the health and educational sectors can support meaningful engagement and lasting change [50].

\section{Whole-school approaches}

A 'whole school approach' for promoting positive mental health, recognises the importance of working collaboratively with all parts of the school community; students, families and staff, whilst acknowledging the impact of local and government policies [18]. Adopting this approach advocates that schools should tackle mental health and well-being through their behaviour policy, curriculum design, care and support for young people, as well as staff, and engagement of parents. Internationally, this has been implemented through schools adopting social and emotional programmes; for example, in the USA, the Collaborative for Academic, Social, Emotional Learning [8], in Australia, KidsMatter [10] and the UK, Social and Emotional Aspects of Learning (SEAL, DCSF, [9]). Where implemented, it has been found to not only support positive mental health, but also raise academic attainment [37].

Despite the outlined benefits of this approach, it is not without challenges. The whole-school approach advocated by many authors (e.g. $[42,48,55])$, may be undermined by:

- lack of adequate support (in terms of staff willingness and/or funding)

- clarity operationalisation, and consistency in terminology used (this would also need to consider how mental health and illness are conceptualised)

- having appropriately trained staff to provide support and supervision, and 
- engaging young people in the development of the promotion of positive mental health.

Furthermore, recognition of the need to have sustainable multi-sector partnership in mental health promotion offers little guidance about who the partnerships should involve or specific roles of stakeholders. However, it would seem appropriate to engage the wider community and include families, as well as young people and their teachers.

\section{Focus and aims of the review}

Research has indicated that many young people worldwide are not well informed about mental health [13, 39, 40, 44, 47], and there is a clear need to raise awareness, educate, and provide interventions that facilitate the maintenance of mental well-being in young populations. Mental health promotions are potentially central to the solution, and therefore, it is unsurprising that many interventions that take this approach have been developed.

The focus of our review is on universal interventions of mental health promotion in schools, recognising that universal and target types require different approaches as the aim of the interventions are different. This review aims to examine advancements in mental health promotion in contemporary education, in the context of global austerity in the last 10 years. In presenting this review, it is necessary to be aware that terminology across the educational and health sectors differs [42] and sometimes mental health promotion is described as positive psychology (e.g. Terjesen et al. [51]) or emotional health (e.g. Kidger et al. [27]). This lack of universal terminology makes reviews complex and comparisons challenging. Therefore, for clarity our searches focused on studies that described interventions as promoting mental health and/or well-being.

\section{Methods}

As noted, the challenge in reviewing mental health promotion is the lack of universality in language and operational definitions of key terms. It is not always clear whether when the term mental health promotion is used, it is consistent with the WHO definition. Additionally, in education, several programmes go under a different title. For example, social and emotional learning (SEAL) is often used and interventions designed to promote effective mastery of social-emotional competencies aim to achieve greater well-being and better school performance by reducing risk factors and promoting protective mechanisms for positive adjustments [20]. For our review, we focused on searching for positive mental health promotion interventions as defined by the WHO, including social and emotional well-being, to capture an inclusive overview of the work that has been done.

\section{Inclusion and exclusion criteria}

To ensure included studies focused on mental health promotion interventions in schools we utilised the literature to facilitate our identification of appropriate inclusion and exclusion criteria. Studies eligible were:

(a) Written in English.

(b) Published between 1 January 2007 and 30 November 2017 for three reasons; (1) because there were reviews conducted in the early millennium that captured earlier work (e.g. Wells et al. [56]); (2) a decade is a sufficient time-frame to examine impact and change; and (3) captures recent policy changes that may impact on design and delivery of interventions.

(c) Universal mental health promotion (or equivalent) (these should be different from targeted approaches as the interventions for universal and targeted interventions have different aims, objectives, intervention type and audience).

(d) Whole-school interventions, programmes, frameworks, models, and tools, involving many levels of school personnel.

(e) Target population was school age (that is, children of any age who are attending school. This spectrum varies internationally, but is generally from 3 to 18 years), and included any type of school (e.g. public, private, special, residential).

(f) Original research.

We also provided parameters by identifying exclusion criteria:

(a) Not published in English.

(b) Not book chapters, editorials or guidance documents.

(c) Not focused on risk factors or related to these.

(d) Not reporting planning and development, and not pilots of interventions (as these would only present feasibility and would not be conclusive).

(e) Not those interventions targeting children with preexisting mental health problems.

\section{Search strategy}

Two large database systems were utilised for the search which captured the multidisciplinary nature of mental health promotion. First, was SCOPUS, a database that captures science, medicine, social science, arts and humanities research. Second, was ERIC, a database of the literature in the field of education. A range of search terms were utilised by two 
of the authors to ensure the searches were consistent. There were three independent searches across the two databases and these were:

(a) Mental health AND promotion AND schools

(b) Positive AND mental AND health AND promotion AND schools AND NOT illness

(c) Mental health promotion AND well-being AND intervention AND schools

The top 100 results for each key-word combination based on relevance were searched as relevance dropped significantly after this point. This produced 25 articles that appeared to be appropriate. These were mapped against criteria and narrowed to 10 intervention studies.

\section{Results}

When matched against the inclusion and exclusion criteria, a total of ten papers were returned. Three of these utilised a qualitative design and seven quantitative design. The literature was well spread globally (e.g. UK, Australia, USA, Sweden, Denmark, Germany, Ireland) and included different interventions, all of which were targeted at the general population of young people in schools. We organised our findings around four main issues: (1) the theoretical framework underpinning the intervention; (2) support, training and supervision for staff implementing the intervention; (3) outcomes of the interventions and (4) long-term impact. The findings were subsequently summarised and an overview of the articles is presented in Table 1.

\section{Theoretical frameworks}

Most interventions were reported to be underpinned by a theoretical framework, but these were variable. Six studies reported a clear theory underpinning the intervention, and two described the theoretical position of the methodology; two of the studies made no explicit reference to theory. Mostly, studies were underpinned by the framework of a whole-school approach and/or a child-centred approach to mental health promotion $[1,11,16,21,32]$, although the underpinning theoretical framework was not always clear in the way it was described. Neilsen et al. [32] integrated this whole-school approach framework in the intervention evaluation with an Action Competence focus, linking democracy, participation and empowerment [7]. Franz and Paulus [17] utilised the theoretical position of a resource-based conceptual theory, which balances internal and external needs and resources (see Becker, [4] [non-English publication] in Franze and Paulus, [17]) and did not make explicit reference to the whole-school framework, but did include school personnel in the implementation.

\section{Support, training, and supervision of staff}

A challenge for any intervention is, in part, dependent upon those who deliver it. Notably, seven of the interventions were delivered by teachers, although in one case this was implied rather than stated. Two of the interventions were delivered by specialists including physiotherapists [22] and educational psychologists [21]. For one intervention, the authors did not provide clear details [11]. The support, training, and supervision of teachers during the intervention was described in five of the seven papers that reported staff involvement. For some, training was provided via a workshop [32] and for others, through training sessions. Some staff had continued support and supervision [29], but many did not. Interventions delivered by school staff were also reported to be supported by instruction manuals. Most of these interventions were described as structured $[1,16,17]$.

\section{Mental health outcomes}

In reviewing the interventions, all but two clearly reported a positive impact. Eight of the ten interventions highlighted some degree of impact and argued that the intervention was a successful mental health promotion tool. Notably, two interventions did not produce such positive results. Lendrum et al. [31] reported that the national SEAL programme had no significant impact, and this was the case in all schools. They noted that there were several barriers to success, including, challenges and confusion regarding implementation, staff skills and training needs, lack of awareness, reluctance of staff, poor communication and limited coordination of the whole-school approach. Similarly, Fitzpatrick et al. [16] found few differences following the comparison of a standard versus an enhanced intervention programme for mental health promotion. They argued that the difference between the enhanced and the standard programme may be too small to have a statistically significant effect on outcomes.

\section{Long-term impact}

Although most of the interventions demonstrated degrees of success in promoting mental health and well-being, the papers were less clear about the sustainability and maintenance of this success. The eight interventions reporting a positive impact highlighted variability in the long-term outcomes, mostly projecting the potential of the intervention and arguing that long-term evaluations are necessary $[1,17,32]$. Two of the interventions were tested over longer 


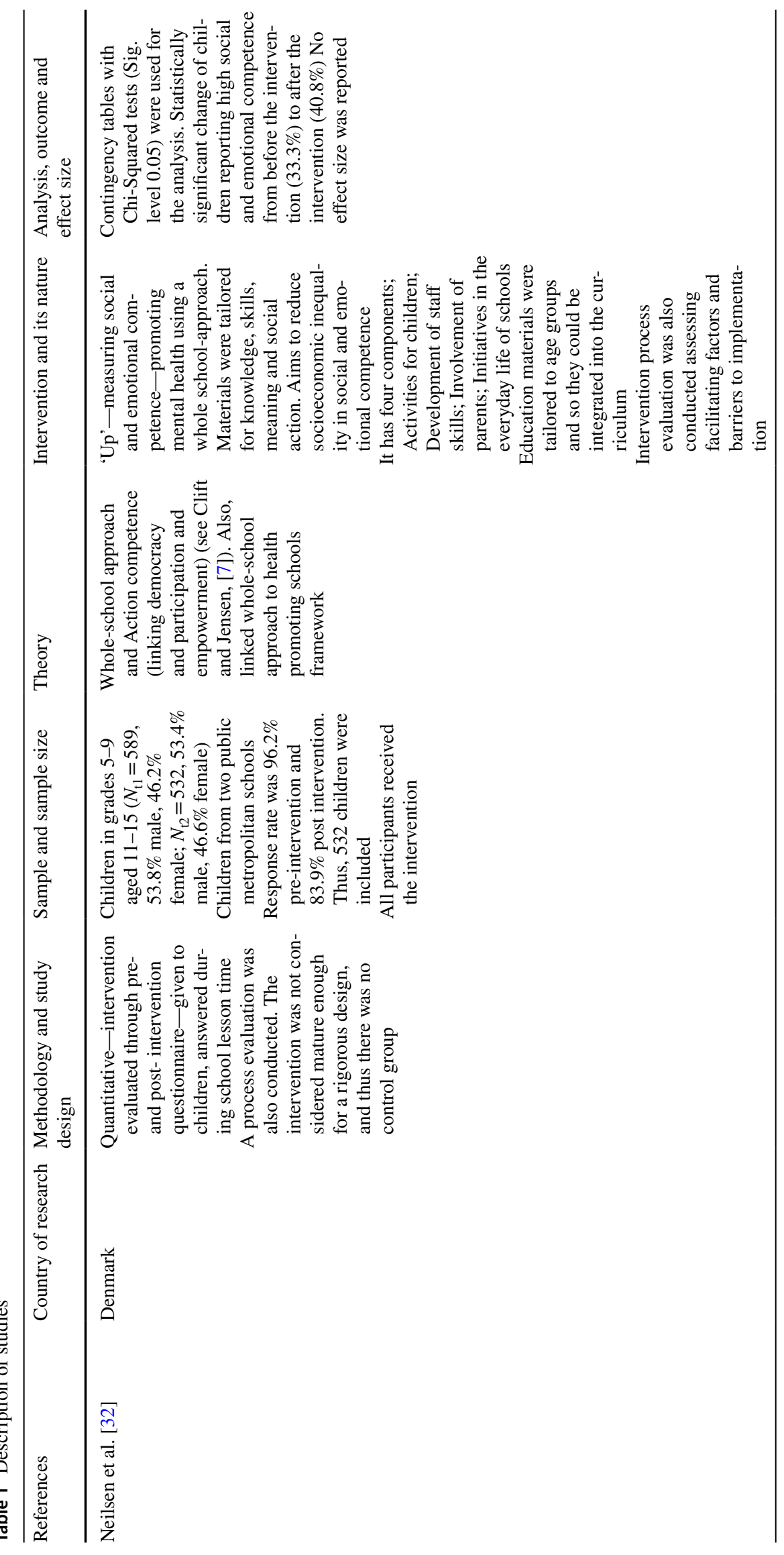




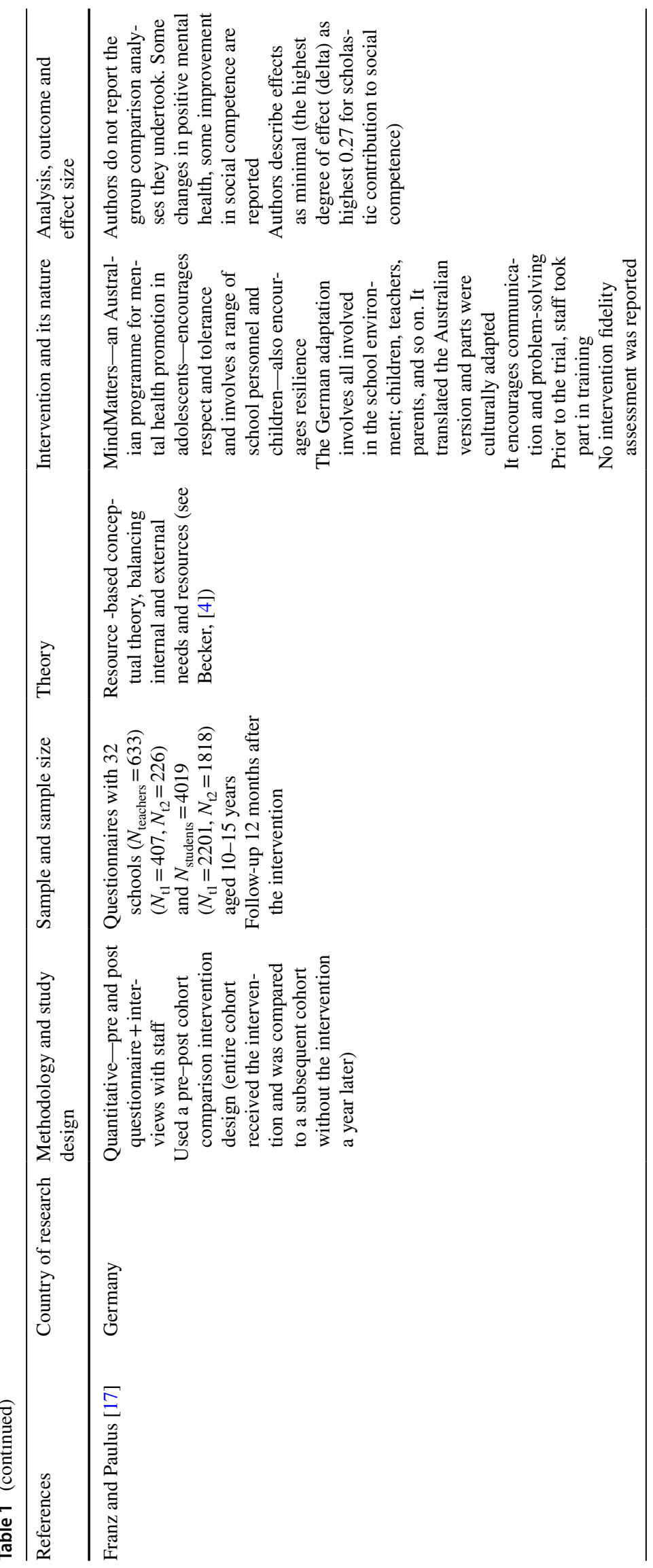

筜 Springer 


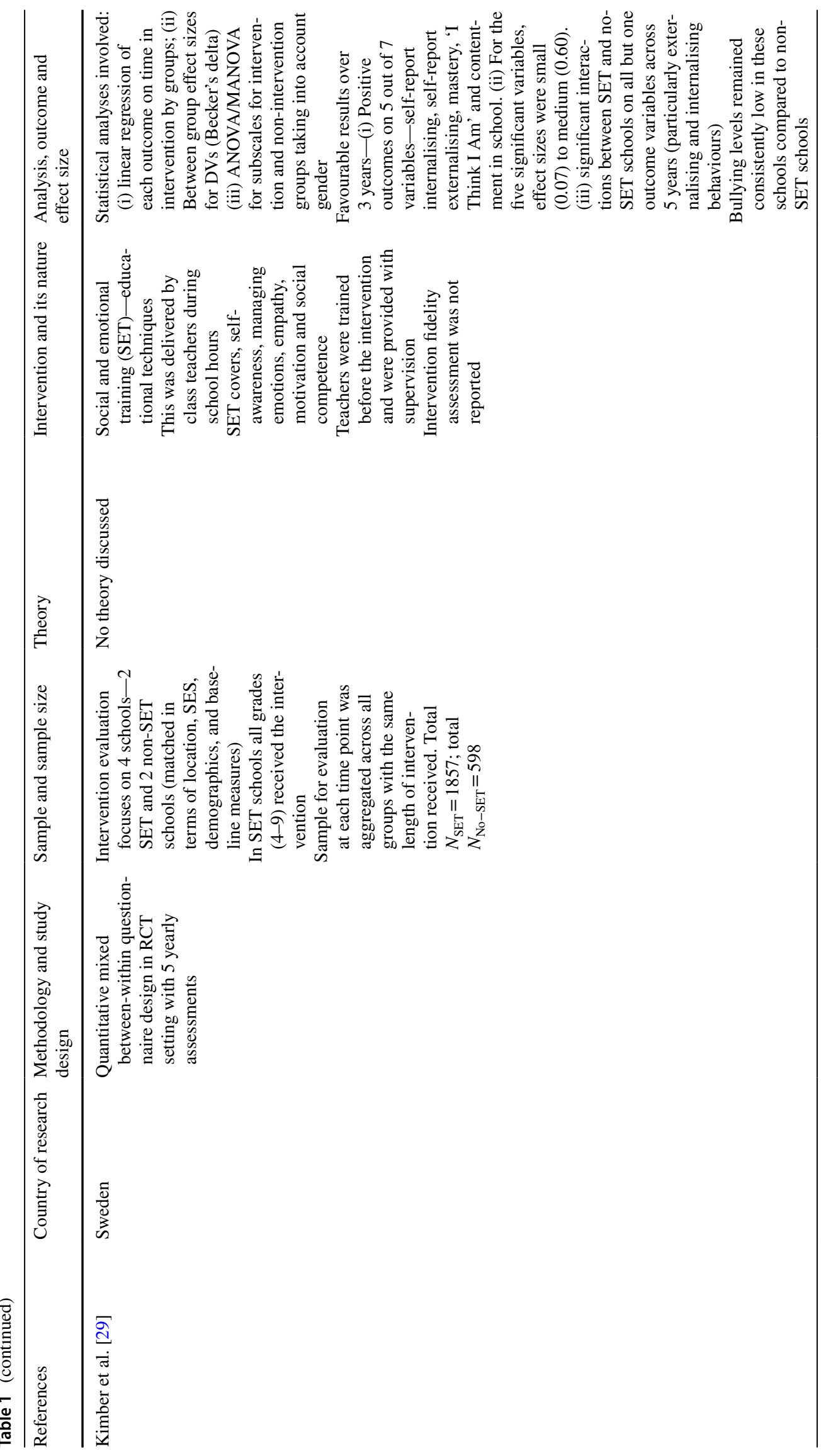




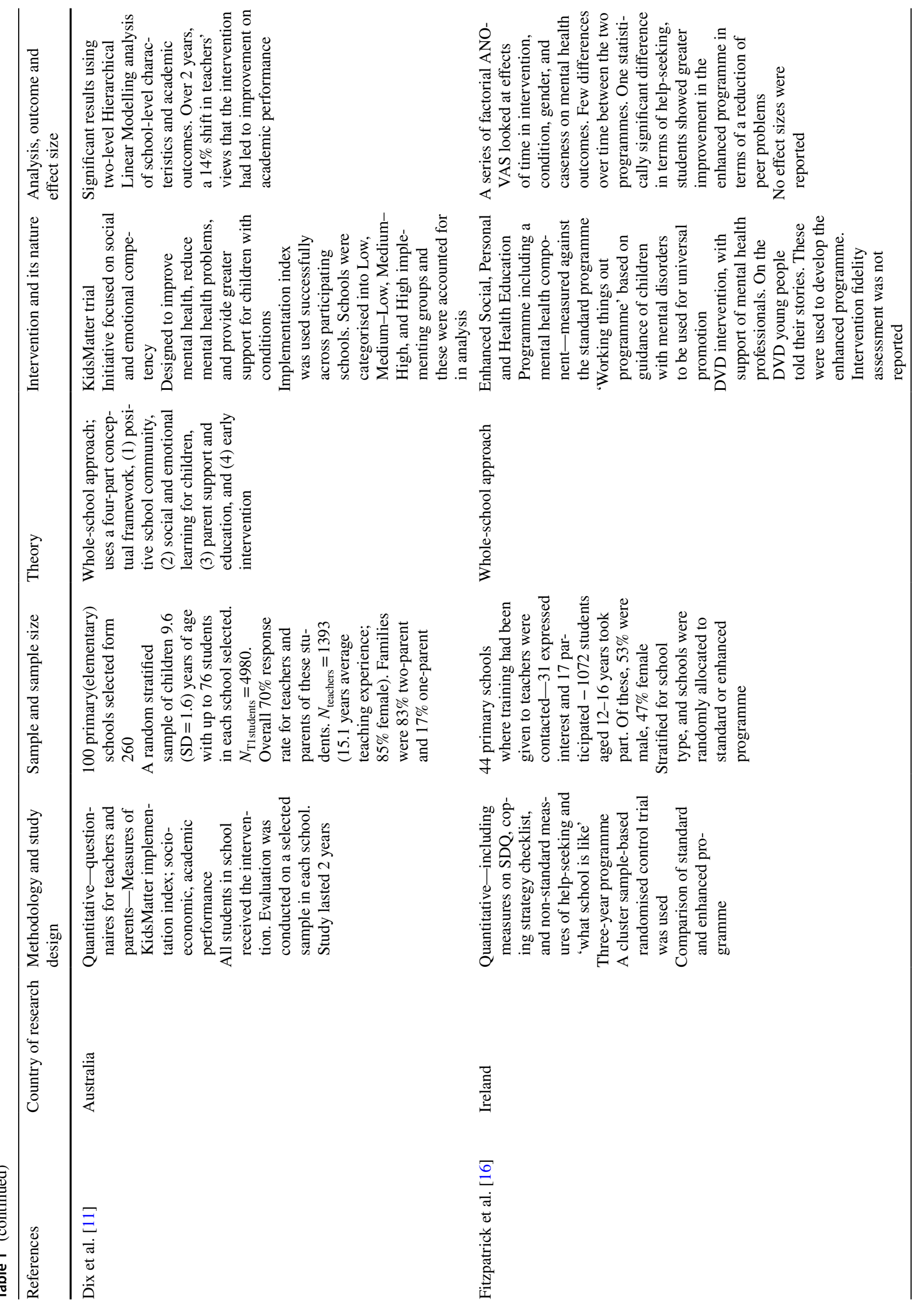




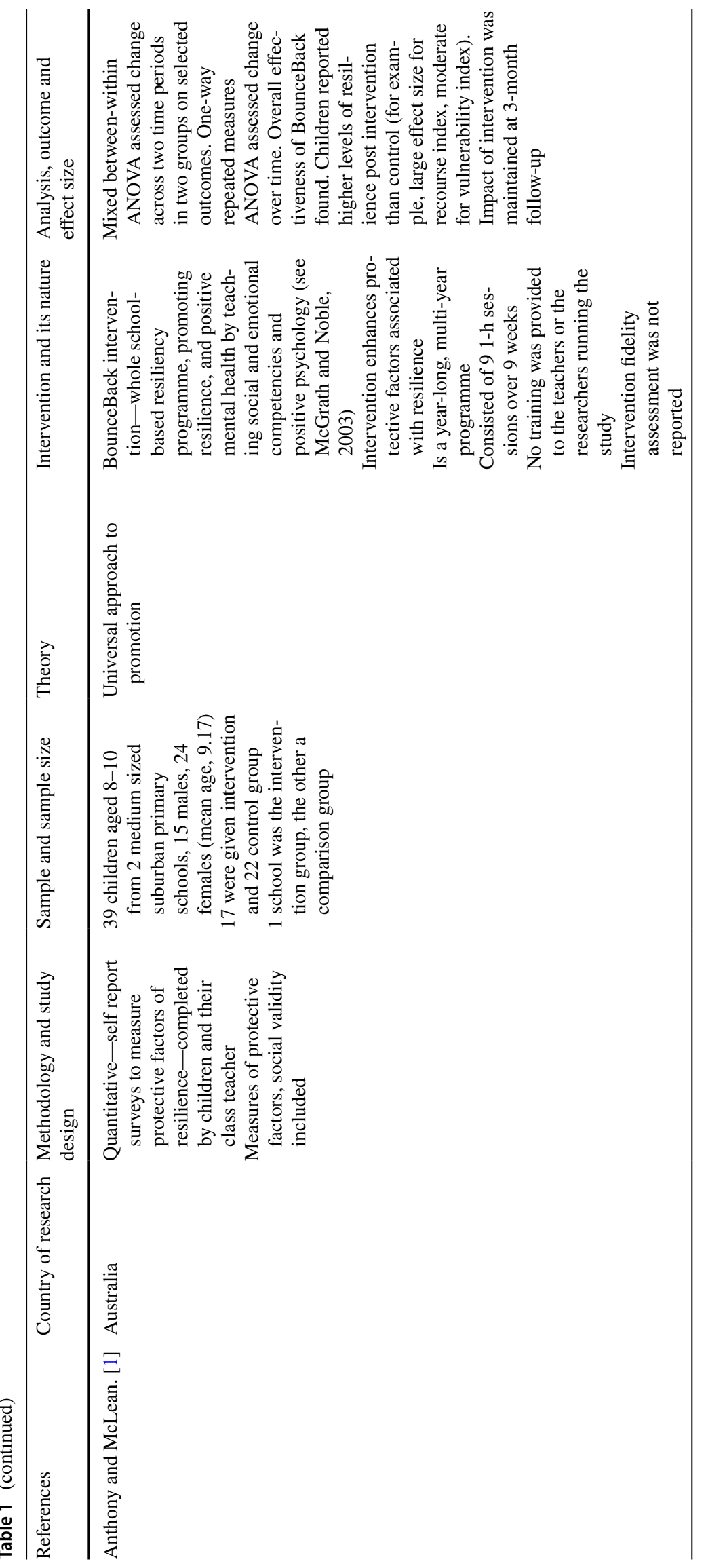




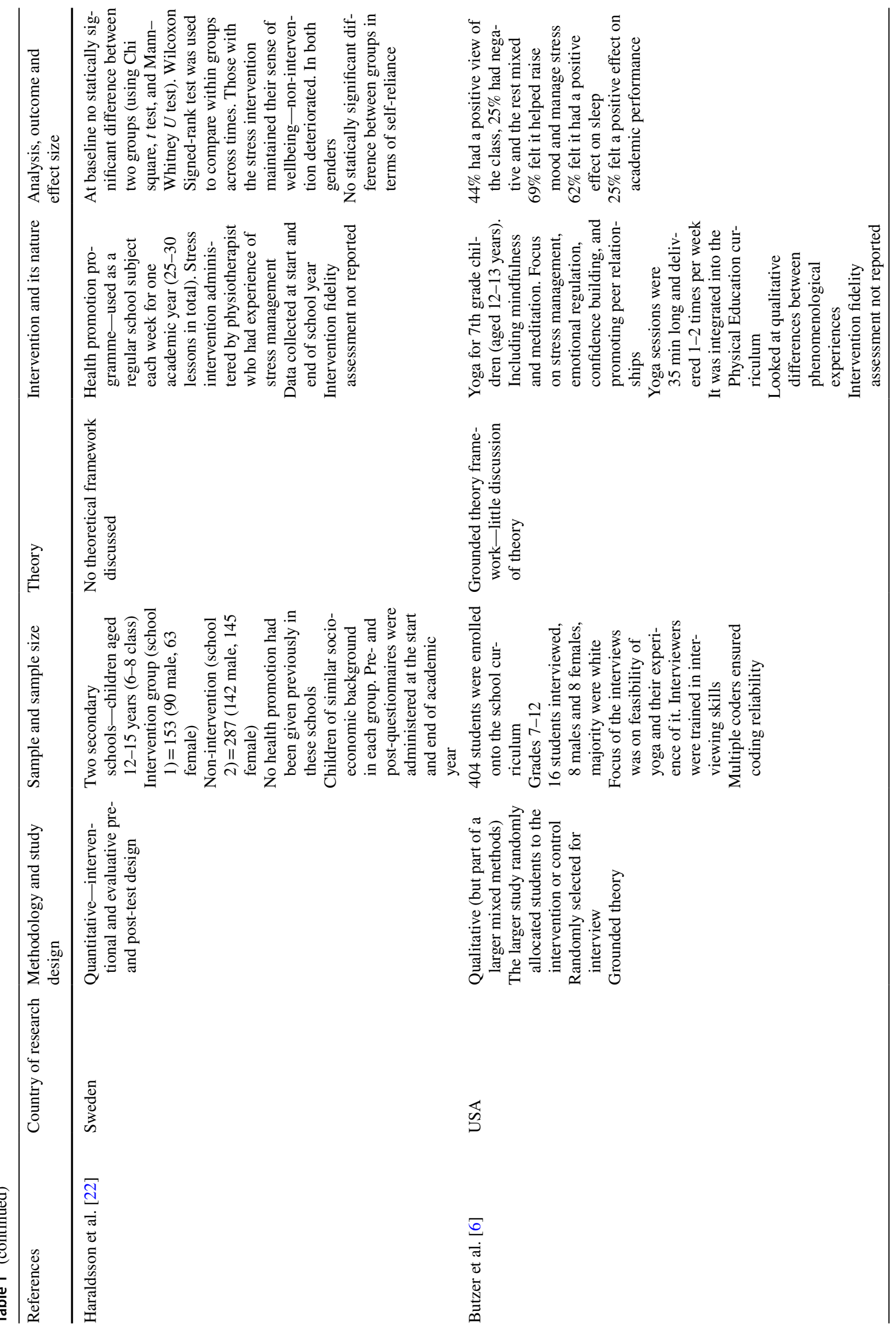




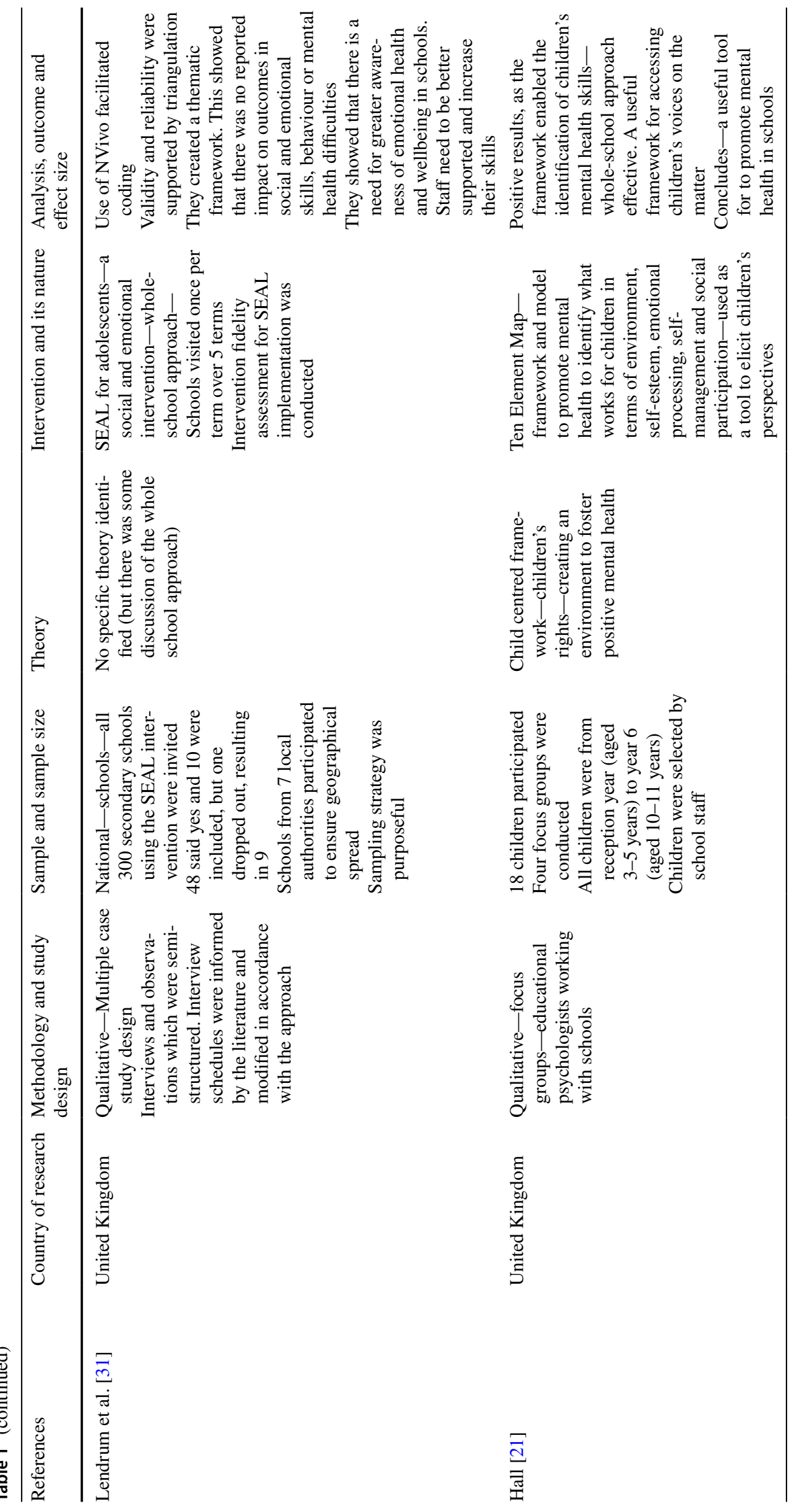


periods of 3- and 2-years [11, 29] respectively, which suggested some sustainability. However, some caution must be exercised as most of the long-term outcomes in terms of mental health promotion were not known and authors argued that commitment from the schools and further evaluations are required in future. Indeed, interventions that showed no change demonstrated that flexibility of the intervention can cause confusion for implementation suggesting the need to balance prescriptive guidelines and flexible adaptations with school culture and ethos [31].

\section{Overall results}

This review has contextualised the broader literature on mental health promotion and specifically explored advancements of universal interventions in the last decade. The results demonstrated that there has been limited advancement of this field. Specifically, we have shown that terminology remains variable, there is still limited evaluation of longterm impacts, and there remains inconsistency regarding the people chosen to run the interventions, with their qualifications and training being varied. Like previous reviews in this area, we demonstrated that methods used were of variable quality, some authors were vague in their descriptions of the intervention, and there was not always clarity regarding sources of funding. Somewhat surprisingly, there was a lack of digital interventions, using AI, informatics, robotics, social media, or internet-based approaches.

\section{Discussion}

Globally, there is continued development and implementation of various interventions in schools designed to promote positive mental health, and yet the effectiveness of most of these is not well evaluated [1]. If we are to move forward and make advances in mental health promotion and help young people cope with daily stresses, we need a better understanding of the outcomes and possible ways of sustaining them. Over the last decade, several mental health promotion interventions have been evaluated and were included in this review.

Universal school-based interventions have great potential to target large populations of young people to promote well-being at a general level. Indeed, this is a common approach taken by schools. Over time, several interventions has emerged based on different theoretical frameworks ([11, $17,21,29,32]$, to name a few). A unifying factor that often underpins or is central to these universal approaches is the whole-school approach, or at least an approach that requires the cooperation of different levels of school personnel, wider communities, and other agencies. Previous reviews over the last couple of decades on the beneficial effects of mental health, social, emotional and educational outcomes have shown that a whole-school approach sustained for more than a year is positive for health promotion and prevention. These conclusions were supported by Weare and Murray [53] who found that a multi-dimensional and integrated wholeschool approach is needed for mental health promotion to be effective and to create positive change in the well-being of young people. A more recent review highlighted that for positive outcomes to be achieved, any intervention must be sequenced in the sense that the activities need to be coordinated, incorporating an active form of learning, focused on personal or social skills and explicitly targeting specific skills rather than positive development [15].

However, these interventions also showcase variability in outcomes, challenges of concepts and ideas, difficulties in implementation and attitudes, and issues of sustainability. Early reviews by Wells and colleagues [56] showed a large variation in type and quality of publications and our review demonstrates that the situation has barely changed since. The quality of evidence has been appraised as generally low-tomoderate, with many studies relying on students' accounts of their own behaviour, with some studies suffering from high attrition rates [30]. Therefore, while popularity of the universal whole-school approach is undeniable, shortcomings of these interventions need to be addressed. Green et al. [19] stated that "while the limited information from the reviews makes it difficult to comment on universal approaches to mental health promotion, whole-school approaches to the promotion of social and emotional health implemented over years appear to be more effective than brief class-based programmes aimed at preventing mental health problems". However, like previous reviews, our findings demonstrated that considerable methodological issues remain.

\section{Challenges of using interventions}

The core challenge for successful mental health promotion is that most of the school-based interventions reported tended to be short-term with little long-term follow-up. Furthermore, they were also often evaluated immediately or shortly after the intervention. However, there is increasing evidence that some long-term effects are emerging and that although effects gradually decrease over time they can remain substantial [54].

Although some whole-school approaches related to mental health promotion have found fewer advantages than others, sometimes this is attributed to a lack of consistent, rigorous and faithful implementation of the overall programme and/or lack of support for teachers administering it [29]. For example, in a survey of 599 primary and 137 secondary schools in the UK, two-thirds of schools adopted universal approaches, but gaps in teacher training and support were identified as problematic [52]. For schools with limited 
resources or those that place high demands on teachers' time, it may be more beneficial that the universal wholeschool approach in the mental health promotion is set aside in favour of a smaller scale targeted intervention that is more manageable and sustainable. The crucial challenge of either model of intervention would be to effectively and consistently engage the learners (that is the young people themselves) in development and delivery.

In attempts to bolster schools' responsibilities for catering for young peoples' mental health, funding for schools in England has been provided to ensure all schools have a trained 'mental health champion' by 2020 [38]. By having an identified and trained responsible member of staff, this may alleviate some of the challenges faced in implementing a whole-school approach. The 'mental health champion' will be able to act as a strategic lead in implementing interventions designed to promote positive mental health, whilst also monitoring the impact and cost effectiveness. However, this raises issues for schools, as training will be central to successful implementation, but training for teachers cannot tackle mental health promotion in isolation from the practical difficulties of supporting children who have diagnosed conditions [41]. Additionally, while training teachers is a positive move to address the large-scale issues, in isolation it will not form the solution as it needs to be part of a continued process supported by greater funding for child mental health [24] otherwise it risks being a "sticking plaster solution" to the challenge [45, n.p]. Currently, the Welsh government is piloting specialist CAHMS workers to act as a link between schools and CAHMS whereby school staff are supported to cater for the mental health of their pupils whilst also having support in place when more specialist interventions are needed [57].

Achieving the goals of mental health promotion, and implementing interventions, relies heavily on good quality evidence, and yet much work in this area is not sufficiently evidence-based [52]. Vostanis et al. argued that there is a clear need to improve this situation. These improvements could include more effective evaluation methodologies (e.g. rationalisation and operationalisation of selected theoretical frameworks and models, methods and instruments used), explicit application procedure of interventions, and details of teacher training and support packages [36]. Evidently, the popularity of a 'one approach fits all' needs to be matched with rigorous systematic development, recognising contributing/challenging factors as well as application and measurement across different populations, school systems, and wider cultural contexts. Additionally, more work needs to include the 'child's voice', to be child-centred and respect children's rights, and therefore, there is a need for more qualitative work in this area.

\section{Strengths and limitations}

This review is not without its limitations. First, to provide a targeted and focused message about mental health promotion in schools, we have been prescriptive in the search terms used to identify the scope of the literature. Given a broader search, we might have included papers that have not utilised specific terminology in their interventions. Additionally, research conducted prior to 2007 was not included, and this work may not have been replicated or evaluated since. These studies were excluded from the review as arguably they may not account for contemporary policy and older reviews may exist which evaluate that work. Second, we have only included results published in English, and therefore, rely on research that has been promoted through English publication streams. While included papers did offer an international perspective in terms of interventions across different educational systems in different countries, the sample remained focused on the developed world. No papers looked at mental health promotion efforts in schools in developing countries, which is an area of great significance in terms of mental health outcomes for young people. This is probably missing from the review due to publishing language barriers and/or research not being undertaken in this area as resources are often even more limited in the developing world. Therefore, the current review and discussion is limited in its applicability to countries with similar development profiles to the ones included. However, arguably, factors of effective and sustainable mental health promotion interventions outlined here could be applicable across variety of cultural contexts, albeit untested.

\section{Directions for future research}

In their review, Weare and Nind [53] identified that the characteristics of high-quality programmes that were successfully implemented include:

- A sound theoretical base with specific, well-defined goals that were communicated effectively.

- Focus on the desired outcomes.

- Explicit guidelines and through training, which is quality assured.

- Complete and accurate implementation.

This list of recommendations is consistent with the need for high-quality training interventions in any field [14]. Weare and Nind [54] argued that much of the evidence related to mental health work in schools would support that these characteristics will be beneficial in implementation, although the benefits may be small and not sustained, as supported by our review findings. The authors, however, argued that even change that is small in statistical terms may 
translate into a significant impact on well-being and this is something that should be explored.

Nonetheless, it is evident from our review, that there is still a need for a stronger and broader evidence base in the field of mental health promotion, which should focus on both universal work and targeted approaches to fully address mental health in our young populations. In terms of intervention development, research has demonstrated that it is essential to include young peoples' views when developing interventions to ensure a child-centred approach and support at a whole-school level [21,35] and thus the co-development of programmes could be helpful. Further to this is the need to develop teachers' understanding, competence and confidence in delivering and sustaining mental health promotion with their pupils [31], as research shows that teachers are resistant to holding too much responsibility in terms of mental health and lack confidence [34]. Methodologically, interventions need to be able to adapt to school culture and available resources while still offering measurable set of outcomes. More attention needs to be paid to the culture of schools as part of any intervention, as there may be little value in implementing programmes when it is already known that the factors needed for their success are not in place at the time or are not sustainable in long-term (e.g. if funding/support expires with termination of the research project). Furthermore, rigour and quality in the evaluation of interventions also needs attention. Programme effectiveness, safety, and cost is not always as rigorous and robust as it could be $[30,33]$ and therefore, attention to the quality of studies is essential for future examinations of interventions. Validation tools can go some way to addressing these issues [5].

\section{Conclusion}

Our review has demonstrated that there is some success for interventions, many of which were underpinned by the whole-school approach or similar frameworks. This was also the case for other intervention types that were not so broad in scope. However, training teachers in delivery was important and long-term outcomes unclear. Thus, building on previous work, we have demonstrated that there remain gaps in knowledge, that there are issues with sustainability of universal approaches, and that success, to some extent, relies on cooperation, training and involvement of the schools and the young people themselves. Furthermore, modes of delivery and the nature of the interventions are important and need to appeal to young people. This could be facilitated by more scoping work in terms of digital health promotion. In a digital age, with digital tools, mobile apps, robotics, social media and the internet all forming a central part in daily life, there is potential to integrate a whole-school approach with digital interventions, and there is room to be creative with universal mental health promotion.

\section{Compliance with ethical standards}

Conflict of interest On behalf of all authors, the corresponding author states that there is no conflict of interest.

Open Access This article is distributed under the terms of the Creative Commons Attribution 4.0 International License (http://creativeco mmons.org/licenses/by/4.0/), which permits unrestricted use, distribution, and reproduction in any medium, provided you give appropriate credit to the original author(s) and the source, provide a link to the Creative Commons license, and indicate if changes were made.

\section{References}

1. Anthony H, McLean L (2015) Promoting mental health at school: short-term effectiveness of a popular school-based resiliency programme. Adv Sch Ment Health Promot 8(4):199-215

2. Atkins MS, Hoagwood KK, Seidman E (2010) Toward the integration of education and mental health in schools. Adm Policy Ment Health Ment Health Serv Res 37:40-47

3. Barnes J (1998) Mental health promotion: a developmental perspective. Psychol Health Med 3:55-69

4. Becker P (1997) Psychologie der seelischen Gesundheit. Band 1: Theorien, Modelle, Diagnostik. Hogrefe, Göttingen

5. Bjørnsen H, Eilertsen ME, Ringdal R, Espnes G, Mosnes U (2017) Positive mental health literacy: development and validation of a measure among Norwegian adolescents. BMC Public Health 17:717-727

6. Butzer B, LoRusso A, Windsor R, Riley F, Frame K, Khalsa S, Conboy L (2017) A qualitative examination of yoga for middle school adolescents. Adv Sch Ment Health Prom 10(3):195-219

7. Clift S, Jensen B (2005) The health promoting school: international advances in theory, evaluation and practice. Danish University of Education Press, Copenhagen

8. Collaborative for academic, social, and emotional learning. https ://casel.org/. Accessed 12 Feb 2018

9. DCSF (2010). Social and emotional aspects of learning (SEAL) programme in secondary schools: national evaluation. Department for Children, Schools and Families, Nottingham

10. Department of Health KidsMatter. https://www.kidsmatter.edu. au/. Accessed 9 Feb 2018

11. Dix K, Slee P, Lawson M (2012) Implementation quality of whole-school mental health promotion and students' academic performance. Child Adolesc Ment Health 17:45-51

12. Dogra N (2010) Social factors that influence child mental health. In: Bhugra D, Morgan C (eds) Principles of social psychiatry, 2nd edn. Wiley-Blackwell, Oxford, pp 295-304

13. Dogra N, Omigbodun O, Adedokun T, Bella T, Ronzoni P, Adesokan A (2012) Nigerian secondary school children's knowledge of and attitudes to mental health and illness. Clin Child Psychol Psychiatry. https://doi.org/10.1177/1359104511410804

14. Dogra N, Parkin A, Gale F, Frake C (2017) A multidisciplinary handbook of child and adolescent mental health for front-line professionals, 2nd edn. Jessica Kingsley Publishers, London

15. Durlak J, Weissberg R, Dymnicki A, Taylor R, Schellinger K (2011) The impact of enhancing students' social and emotional 
learning: a meta-analysis of school-based universal interventions. Child Dev 82(1):405-432

16. Fitzpatrick C, Conlon A, Cleary A, Power M, King F, Guerin $S$ (2013) Enhancing the mental health promotion component of health and personal development programme in Irish schools. Adv Sch Ment Health Promot 6(2):122-138

17. Franze M, Paulus P (2009) MindMatters-a programme for the promotion of mental health in primary and secondary schools: results of an evaluation of the German Language Adaptation. Health Educ 109(4):369-379

18. Graetz B, Littlefield L, Trinder M, Dobia B, Souter M, Champion C, Boucher S, Killick-Moran C, Cummins R (2008) KidsMatter: a population health model to support student mental health and well-being in primary schools. Int $\mathbf{J}$ Ment Health Promot 10(4):13-20

19. Green J, Howes F, Waters E, Maher E, Oberklaid F (2005) Promoting the social and emotional health of primary school-aged children, reviewing the evidence base for school-based interventions. Int J Ment Health Promot 7(3):30-36

20. Guerra NG, Bradshaw CP (2008) Re-thinking the prevention of problem behaviors and positive youth development: core competencies for positive youth development and risk prevention. New Dir Child Adolesc Dev 122:1-17

21. Hall S (2010) Supporting mental health and well-being at a wholeschool level: listening to and acting upon children's views. Emot Behav Diffic 15(4):323-339

22. Haraldsson K, Lindgen EC, Fridlund B, Baigi A, Lydell M, Marklund B (2008) Evaluation of a school-based health promotion programme for adolescents aged $12-15$ years with focus on well-being related to stress. Public Health 122:25-33

23. Humphrey N, Lendrum A, Wigelsworth M (2010) Social and emotional aspects of learning (SEAL) programme in secondary schools: national evaluation. DFE

24. Karim K, O'Reilly M (2017) Comment on Public Health England's investment in mental health training for schools. https:// www2.le.ac.uk/offices/press/think-leicester/health-and-medic ine/2017/comment-on-public-health-england-investment-inmental-health-training-for-schools. Accessed 12 Feb 2018

25. Kessler R, Berglund O, Demler R, Jin R, Walters E (2005) Lifetime prevalence and age-of-onset distributions of DSM-IV disorders in the National Comorbidity Survey replication. Arch Gen Psychiatry 62:593-602

26. (The) Key (2017) State of Education Survey Report 2017. Rising to the challenge: examining the pressures of schools and how they are responding. https://view.joomag.com/state-of-education-repor t-2017/0676372001494577623. Accessed 12 Feb 2018

27. Kidger J, Donovan J, Biddle L, Campbell R, Gunnell D (2009) Supporting adolescent emotional health in schools: a mixed methods study of student and staff views in England. BMC Public Health 9:403-421

28. Kieling C, Baker-Henningham H, Belfer M, Conti G, Ertem I, Omigbodun O, Rohde LA, Srinath S, Ulkuer N, Rahman A (2011) Child and adolescent mental health worldwide: evidence for action. Lancet. https://doi.org/10.1016/S0140-6736(11)60827 $-1$

29. Kimber B, Sandell S, Bremberg S (2008) Social and emotional training in Swedish schools for the promotion of mental health: an effectiveness study of 5 years of intervention. Health Educ Res 23(6):931-940

30. Langford R, Bonell CP, Jones HE, Pouliou T, Murphy SM, Waters E, Komro KA, Gibbs LF, Magnus D, Campbell R (2014) The WHO Health Promoting School framework for improving the health and well-being of students and their academic achievement. Cochrane Database Syst Rev. https://doi.org/10.1002/14651858. CD008958.pub2
31. Lendrum A, Humphrey N, Wigelsworth M (2013) Social and emotional aspects of learning (SEAL) for secondary schools: implementation difficulties and their implications for schoolbased mental health promotion. Child Adolesc MentHealth 18(3):158-164

32. Nielsen L, Meilstrup C, Nelausen M, Koushede V, Holstein B (2015) Promotion of social and emotional competence: experiences from a mental health intervention applying a whole school approach. Health Educ 115:339-356

33. O'Mara L, Lind C (2013) What do we know about school mental health promotion programmes for children and youth? Adv Sch Ment Health Promot 6(2):203-224

34. O'Reilly M, Adams S, Whiteman N, Hughes J, Reilly P, Dogra N (2018) Whose responsibility is adolescent's mental health in the UK? Perspectives of key stakeholders. Sch Ment Health. https:// doi.org/10.1007/s12310-018-9263-6

35. O'Reilly M, Dogra N, Hughes J, Reilly P, Whiteman N (2017) Written evidence for parliament: mental health in schools. http:// data.parliament.uk/writtenevidence/committeeevidence.svc/evide ncedocument/health-committee/children-and-young-peoplesmental-healththe-role-of-education/written/45583.pdf. Accessed 12 Feb 2018

36. Power M, Cleary D, Fitzpatrick C (2008) Mental health promotion in Irish schools: a selective review. Adv Sch Ment Health Promot Vol 1(1):5-15

37. Public Health England (2015) Promoting children and young people's emotional health and well-being: a whole school and college approach. Public Health England, London. https://www. gov.uk/government/publications/promoting-children-and-young -peoples-emotional-health-and-well-being. Accessed 12 Feb 2018

38. Public Health England (2017) Secondary school staff get mental health 'first aid' training. https://www.gov.uk/government /news/secondary-school-staff-get-mental-health-first-aid-train ing. Accessed 12 Feb 2018

39. Ronzoni P, Dogra N, Omigbodun O, Bella T, Atitola O (2010) Stigmatization of mental illness among Nigerian schoolchildren. Int J Soc Psychiatry. https://doi.org/10.1177/002076400934123 0

40. Rose D, Thornicroft G, Pinfold V, Kassam A (2007) 250 labels used to stigmatise people with mental illness. BioMedCentral Health Serv Res. https://doi.org/10.1186/1472-6963-7-97

41. Rothi D, Leavey G, Best R (2008) On the front-line: teachers as active observers of pupils' mental health. Teach Teach Educ 24(5):1217-1231

42. Rowling L (2009) Strengthening 'school' in school mental health promotion. Health Educ 109(4):357-368

43. Scottish Government (2017) Mental health strategy 2017-2027 http://www.gov.scot/Publications/2017/03/1750/5 Accessed 10 Apr 2018

44. Sessa B (2005) I'll have to lie about where I've been. Young Minds Mag 76:34-5

45. Sims-Schouten W (2017) Mental health first aid training in schools is a sticking-plaster solution. https://theconversation.com/ mental-health-first-aid-training-in-schools-is-a-sticking-plastersolution-80166 Accessed 12 Feb 2018

46. Sroufe A, Rutter M (1984) The domain of developmental psychopathology. J Child Dev 55:705-711

47. Stengård E, Appelqvist-Schmidlechner K (2010) Mental health promotion in young people: an investment for the future. World Health Organisation, Geneva

48. Stewart-Brown S. What is the evidence on school health promotion in improving or preventing disease and, specifically, what is the effectiveness of the health promoting schools approach? Copenhagen: WHO Regional Office for Europe (Health Evidence 
Network Report). http://www.euro.who.int/_data/assets/pdf_ file/0007/74653/E88185.pdf. Accessed 8 Feb 2017

49. Sturgeon S (2007) Promoting mental health as an essential aspect of health promotion. Health Promot Int 21(S1):36-41

50. Svirydzenka N, Bone C, Dogra N (2014) Schoolchildren's perspectives on the meaning of mental health. J Public Ment Health. https://doi.org/10.1108/JPMH-09-2012-0003

51. Terjesen M, Jacofsky M, Froh J, DiGiuseppe R (2004) Integrating positive psychology into schools: implications for practice. Psychol Sch. https://doi.org/10.1002/pits.10148/full

52. Vostanis P, Humphrey N, Fitzgerald-Yau N, Wolpert M (2013) How do schools promote emotional well-being among their pupils? Findings from a national scoping survey of mental health provision in English schools. Child Adolesc Ment Health 18(3):151-157

53. Weare K, Murrary M (2004) Building a sustainable approach to mental health work in schools. Int J Health Promot 6(2):53-59
54. Weare K, Nind M (2011) Mental health promotion and problem prevention in schools: what does the evidence say? Health Promot Int 26:i29-i69

55. Weist MD, Murray M (2007) Advancing school mental health promotion globally. J Adv Sch Ment Health Promot. https://doi. org/10.1080/1754730X.2008.9715740

56. Wells J, Barlow J, Stewart-Brown S (2003) A systematic review of universal approaches to mental health promotion in schools. Health Educ 103(4):197-220

57. Welsh Government (2017) Written statement-providing for the emotional and mental health needs of young people in school. http://gov.wales/about/cabinet/cabinetstatements/2017/mentalheal thneeds/?lang=en Accessed 10 Apr 2018

58. (The) World Health Organisation (WHO) (2016) Mental health: strengthening our response. http://www.who.int/mediacentre/facts heets/fs220/en/. Accessed 23 Mar 2017 